\title{
CRESCIMENTO E RESISTÊNCIA À SECA DE LEUCENA EM SOLO DE CERRADO ${ }^{1}$
}

\author{
SONIA CRISTINA JULIANO GUALTIERI DE ANDRADE PEREZ² e SILMARA CRISTINA FANTI ${ }^{3}$
}

RESUMO - Plantas envasadas de Leucaena leucocephala Lam. (De Witt) foram cultivadas em casa de vegetação sob $30 \%$ de sombreamento artificial, em solo de cerrado, com adição de 0, 750, 1.500 e $3.000 \mathrm{~kg} \mathrm{ha}^{-1}$ de NPK (4-14-8). Aos 180 dias após a emergência (DAE), as plantas crescidas em solo sem adubo químico apresentaram os menores valores de taxa de crescimento relativo $\left(\mathrm{TCR}=0,028 \mathrm{~g} \mathrm{~g}^{-1} \mathrm{dia}^{-1}\right)$, biomassa total $(5,2 \mathrm{~g})$, taxa assimilatória líquida $\left(\mathrm{TAL}=4,2.10^{-4} \mathrm{~g} \mathrm{~cm}^{-2} \mathrm{dia}^{-1}\right)$, e não produziram nem flores nem vagens. Entre as plantas cultivadas em solo fertilizado, as que receberam maiores quantidades de adubo químico apresentaram maiores valores de biomassa total e área foliar, a partir de 90 DAE. Porém, os maiores valores de TCR $\left(43,92.10^{-4} \mathrm{~g} \mathrm{~g}^{-1} \mathrm{dia}^{-1}\right)$ e TAL $\left(15,01 \mathrm{~g} \mathrm{~cm}^{-2} \mathrm{dia}^{-1}\right)$ foram obtidos nas plantas crescidas em solo com $750 \mathrm{~kg} \mathrm{ha}^{-1} \mathrm{de}$ NPK. A presença de flores e vagens nas plantas que receberam 1.500 e $3.000 \mathrm{~kg} \mathrm{ha}^{-1}$ de NPK ocorreu a partir dos 120 DAE, e aos 150 DAE se iniciou o processo de abscisão foliar nos vegetais crescidos em todos os tratamentos, com conseqüente redução da área foliar, TAL e TCR. Na presença de estresse hídrico simulado, as plantas com 90 DAE mostraram-se mais resistentes que as de 30 dias. Porém, nos dois casos, as plantas mais tolerantes à dessecação foram as crescidas em solo com maiores teores de NPK, e um ajuste osmótico auxiliou as plantas a sobreviverem durante o período da seca.

Termos para indexação: Leucaena leucocephala, análise de crescimento, estresse hídrico.

\section{GROWTH AND DROUGHT RESISTENCE OF LEUCAENA IN “CERRADO” SOIL}

\begin{abstract}
Leucaena leucocephala Lam. (De Witt) plants were cultivated in a growth chamber, with $30 \%$ of artificial shading and in "cerrado" soil fertilized or not with addition of $0,750,1,500$ and $3,000 \mathrm{~kg} \mathrm{ha}^{-1} \mathrm{NPK}$, in Brazil. At 180 days after emergence, plants grown in soil without fertilization presented the lowest values of relative growth rate $\left(\mathrm{TCR}=0.028 \mathrm{~g} \mathrm{~g}^{-1}\right.$ day $\left.^{-1}\right)$, total biomass $(5.2 \mathrm{~g})$, net assimilation rate $\left(\mathrm{TAL}=4.2 .10^{-4} \mathrm{~g} \mathrm{~cm}^{-2} \mathrm{day}^{-1}\right)$ and did not produce neither flowers or fruit. Among plants grown in fertilized soil, the highest values of TCR $\left(43.92 .10^{-4} \mathrm{~g} \mathrm{~g}^{-1} \mathrm{dia}^{-1}\right)$ and TAL $\left(15.01 \mathrm{~g} \mathrm{~cm}^{-2}\right.$ day $\left.^{-1}\right)$ occurred in leucaenas fertilized with $750 \mathrm{~kg} \mathrm{ha}^{-1} \mathrm{NPK}$. Plants fertilized with 1,500 and 3,000 kg ha-1 produced flowers and fruit since 120 days after emergence. Leaf senescence process began at 150 days after emergence, reducing the leaf area, TAL and TCR. Resistence to water stress was greater in 90 day-old plants than in 30 day-old ones. In both cases, the most desiccation resistant plants were those grown in soil with higher NPK rates. An osmotic adjustment aided the plants to survive during the drought period.
\end{abstract}

Index terms: Leucaena leucocephala, growth analysis, water stress.

\footnotetext{
${ }^{1}$ Aceito para publicação em 19 de maio de 1998. Trabalho realizado com apoio do CNPq.

${ }^{2}$ Bióloga, Dra , Prof Adjunta, Dep. Botânica, UFSCar, Rodovia Washington Luiz, Km 235, Caixa Postal 676, CEP 13565-905 São Carlos, SP. E-mail: dscp@power.ufscar.br

${ }^{3}$ Bióloga, aluna do Curso de Doutorado em Ecologia e Recursos Naturais, UFSCar. Bolsista do CNPq.
}

\section{INTRODUÇ̃̃OO}

Estudos visando à análise dos efeitos das condições ambientais sobre o crescimento vegetal são de grande importância na seleção de material vegetal com boa adaptação às condições locais, que poderá ser utilizado na produção de mudas para recolonização de áreas, para a alimentação de animais e 
para o melhoramento do solo (Salerno \& Seiffert, 1986). Além disso, pesquisas também devem ser feitas visando indicar a utilização de insumos agrícolas de baixo custo, tais como adubo verde e adubo orgânico aplicados isoladamente ou na presença de fertilizante mineral (Nogueira et al., 1992).

O interesse no uso de leguminosas arbóreas vem aumentando de forma considerável, principalmente em face da habilidade de fixar o $\mathrm{N}$ no solo e produzir matéria orgânica geralmente rica em $\mathrm{N}, \mathrm{P}, \mathrm{K}$, $\mathrm{Ca}$, o que aumenta a qualidade do solo em agrossistemas tropicais (Miyasaka et al., 1983).

Entre os vários trabalhos realizados com a espécie Leucaena leucocephala, pode-se citar os experimentos conduzidos por Salerno \& Vetterle (1983) e Salerno \& Tcacenco (1983) para a avaliação de produção de matéria seca. Seiffert \& Thiago (1983), Salerno \& Vetterle (1983) e Salerno \& Tcacenco (1983) analisaram o efeito da calagem e da adubação fosfatada no crescimento dessa forrageira. Schunke, citado por Seiffert \& Thiago (1983), apresenta recomendações gerais para adubação dos solos de cerrado para o plantio posterior de Leucaena.

Pesquisas visando à adaptação de plantas em solos com diferentes disponibilidades hídricas são também importantes. Nesse aspecto, têm-se os resultados obtidos por Lima Filho et al. (1992), com o plantio de Leucaena sob deficiência hídrica, e os de Seiffert \& Thiago (1983), que relatam a tolerância da leucena à seca e à má drenagem. Os trabalhos de Skerman (1977), Blom (1980) e Seiffert \& Thiago (1983) definem áreas mais adequadas ao cultivo de Leucaena com relação à precipitação pluvial.

As plantas conhecidas no Brasil como leucena (Leucaena leucocephala) Lam. (De Witt) são árvores ou arbustos perenes (National Academy of Science, 1977), pertencentes à família Leguminosae (Mitidieri, 1983). Até o momento, foram classificadas doze espécies do gênero Leucaena, sendo Leucaena leucocephala a que apresenta maior importância em nível internacional (Brewbaker, 1987).

Leucaena leucocephala tipo Peru, cultivar Cunninghan, utilizada neste trabalho, é uma forrageira de porte arbóreo que atinge até $15 \mathrm{~m}$ de altura, apresentando intensa ramificação e grande quantidade de folhagem (National Academy of Science, 1977).
A importância econômica dessa espécie se deve ao seu valor como árvore de sombreamento e adubo verde, e existe crescente interesse na utilização de Leucaena nos trópicos para restauração da fertilidade dos solos, forragem e recuperação de áreas degradadas (Freitas et al., 1991), uma vez que ela se desenvolve bem em encostas íngremes, solos marginais e regiões com grandes períodos de seca (Lima, 1982).

Este trabalho objetivou avaliar o crescimento e a resistência à seca de plantas de leucena cultivadas em casa de vegetação, em solo de cerrado com teores de NPK.

\section{MATERIAL E MÉTODOS}

Os experimentos foram conduzidos na Universidade Federal de São Carlos, em casa de vegetação, com $30 \%$ de sombreamento artificial, no município de São Carlos, região central do Estado de São Paulo $\left(22^{\circ}-22^{\circ} 30^{\prime} \mathrm{S}\right.$ e $47^{\circ} 30^{\prime}-48^{\circ} \mathrm{W}$ ), numa altitude média de $850 \mathrm{~m}$.

De acordo com Camargo et al. (1974), segundo classificação de Köppen, o clima da região é do tipo CWa, tropical com inverno seco e verão quente e úmido, distinguindo-se duas estações características: a seca (nos meses de março a setembro) e a chuvosa (outubro a fevereiro). A temperatura média anual é de $21^{\circ} \mathrm{C}$, e a precipitação anual, de $1.520 \mathrm{~mm}$ (Tabela 1).

Utilizou-se um Latossolo Vermelho-Amarelo, de textura franco-arenosa, com $2,3 \%$ de matéria orgânica e $\mathrm{pH}=4,6$, coletado na camada $0-0,2 \mathrm{~m}$ (Tabela 2 ).

O solo foi espalhado sobre uma lona de plástico, secado ao ar, adubado com NPK (4-14-8) nas proporções de $0,750,1.500$ e $3.000 \mathrm{~kg} \mathrm{ha}^{-1}$ e distribuído em sacos de polietileno com capacidade de $11 \mathrm{~kg}$.

O delineamento experimental foi inteiramente casualizado, em esquema fatorial de $4 \times 6 \times 3$, correspondente a quatro doses de fertilização, seis épocas de coleta e três repetições. Em cada vaso foram plantadas três plântulas, provenientes da germinação em laboratório de sementes de Leucaena leucocephala tipo Peru, cultivar Cunninghan, provenientes da Embrapa-Centro de Pesquisa de Pecuária do Sudeste (CPPSE), localizada em São Carlos, SP. O desbaste foi realizado dez dias após a emergência (DAE), deixando-se apenas uma planta por recipiente. A irrigação foi feita diariamente, até a água começar a escorrer pelos furos na base dos sacos de plástico.

De 30 a 180 DAE, com intervalos de 30 dias, as plantas foram coletadas para análise de crescimento. Para determinação da matéria seca, o material amostrado foi se- 
parado em raiz, caule, folhas, flores e frutos, e colocado em estufa, com ventilação forçada a $85^{\circ} \mathrm{C}$, até atingir peso constante.

Os parâmetros biométricos e fisiológicos foram calculados por meio de fórmulas citadas em Benincasa (1988): a) altura do caule $(\mathrm{cm})$ : comprimento do caule, do solo até o ápice da planta;

b)área foliar $\left(\mathrm{cm}^{2}\right)$ : comprimento e largura dos folíolos; c) razão de área foliar (RAF, $\mathrm{cm}^{2} \mathrm{~g}^{-1}$ ): é um parâmetro morfofisiológico, que expressa a área foliar útil para a fotossíntese. É definida como o quociente entre área foliar (AF) e matéria seca total da planta (PST);

d) área foliar específica (AFE, $\mathrm{cm}^{2} \mathrm{~g}^{-1}$ ): é um componente morfológico e anatômico da RAF, relacionando a superfície foliar com o peso da matéria seca da folha. (Área foliar específica é definida como a razão entre a área foliar (AF) e a matéria seca das folhas (PSF));

e) razão de peso foliar (RPF): é um componente da razão de área foliar, dada pela razão entre o peso da matéria seca retida nas folhas (PSF) e o peso da matéria seca acumulada na planta toda (PST);

f) taxa assimilatória líquida (TAL, $\mathrm{g} \mathrm{cm}^{-2}$ ):

$\mathrm{TAL}=\frac{\operatorname{PST}(\mathrm{n})-\mathrm{PST}(\mathrm{n}-1)}{\mathrm{Tn}-\mathrm{T}(\mathrm{n}-1)} \times \frac{\operatorname{Ln} \cdot \mathrm{AFn}-\mathrm{Ln} \cdot \mathrm{AF}(\mathrm{n}-1)}{\operatorname{AFn}-\operatorname{AF}(\mathrm{n}-1)}$

onde:

n: número da coleta;

PST: peso da matéria seca total (g);

Ln: logaritmo neperiano;

T: tempo em dias;

$\mathrm{AF}$ : área foliar $\left(\mathrm{cm}^{2}\right)$;

g) taxa de crescimento relativo (TCR):

$$
\mathrm{TCR}=\mathrm{TAL} \times \frac{\mathrm{RAFn}+\mathrm{RAF}(\mathrm{n}-1)}{2}
$$

onde:

n: número de coletas;

TAL: taxa assimilatória líquida;

RAF: razão de área foliar;

h) taxa de crescimento absoluto (TCA):

$\mathrm{TCA}=(\mathrm{P} 2-\mathrm{P} 1) /(\mathrm{T} 2-\mathrm{T} 1)$

onde:

P1 e P2: peso da matéria seca;

T1 e T2: períodos sucessivos das coletas;

i) distribuição de matéria seca: é a porcentagem de matéria seca de cada órgão em relação à matéria seca total, ao longo dos períodos avaliados. Esse parâmetro permite inferir outro processo fisiológico muito pouco estudado, que é a translocação orgânica; j) taxa fotossintética (TF): é definida como a taxa assimilatória líquida, multiplicada por $\mathrm{K} / \mathrm{h}$, onde $\mathrm{K}$ é o fator de conversão de quantidade de matéria seca em quantidade de gás carbônico absorvido e equivale a 1,65, e h é o fotoperíodo (considerado de 12 horas) conforme Paulilo et al. (1993):

$$
\mathrm{TF}=\mathrm{TAL} \times \frac{\mathrm{K}}{\mathrm{h}}\left(\mathrm{g} \mathrm{cm}^{-2} \operatorname{dias}^{-1}\right) .
$$

Para a avaliação das relações hídricas da Leucaena leucocephala, foram utilizadas plantas com 30 e 90 DAE. $\mathrm{O}$ estresse hídrico foi induzido pela suspensão da rega, e os seguintes parâmetros foram analisados: a) potencial hídrico, cujas medições foram efetuadas quase que diariamente, desde a aplicação do estresse até as plantas apresentarem sinais de murcha, com auxílio de uma câmara de pressão (Scholander et al., 1964, 1965). Essas determinações foram realizadas pela manhã (entre $8 \mathrm{~h}$ e $8 \mathrm{~h} 30$ ), em duas ou três repetições; b) potencial osmótico: avaliado com uma câmara de pressão, mediante a construção de uma curva de pressão aplicada x volume de seiva expelida, de acordo com o método proposto por Melkonian et al. (1982) e Gupta \& Berkowitz (1987). Esse procedimento foi adotado antes e após o estresse, com duas ou três repetições, dependendo da qualidade da curva obtida, conforme especificações de Melkonian et al. (1982).

Após um período de 20 ou 30 dias da aplicação do estresse em plantas com 30 e 90 DAE, respectivamente, a irrigação foi feita novamente, e realizadas as medições de

TABELA 1. Valores médios mensais de temperaturas mínima e máxima $\left({ }^{\circ} \mathrm{C}\right)$ e precipitação (mm).

\begin{tabular}{lccc}
\hline \multirow{2}{*}{ Período } & \multicolumn{2}{c}{ Temperaturas médias } & \multirow{2}{*}{ Precipitação } \\
\cline { 2 - 3 } & Máxima & Mínima & \\
\hline Dezembro/1993 & 26,4 & 19,2 & 198,0 \\
Janeiro/1994 & 27,6 & 17,9 & 317,0 \\
Fevereiro/1994 & 30,7 & 19,1 & 157,6 \\
Março/1994 & 27,4 & 17,4 & 152,5 \\
Abril/1994 & 27,0 & 16,0 & 123,6 \\
Maio/1994 & 26,6 & 13,2 & 32,2 \\
Junho/1994 & 23,6 & 10,2 & 58,2 \\
Julho/1994 & 25,0 & 10,3 & 39,9 \\
Agosto/1994 & 27,0 & 10,9 & 0,0 \\
Setembro/1994 & 30,2 & 14,4 & 14,2 \\
Outubro/1994 & 31,1 & 17,9 & 149,4 \\
Novembro/1994 & 28,8 & 17,7 & 156,9 \\
Dezembro/1994 & 29,1 & 19,0 & 263,0 \\
\hline
\end{tabular}

Fonte: Estação Meteorológica da Embrapa-Centro de Pesquisa de Pecuária do Sudeste. 
TABELA 2. Análise química e física do solo

\begin{tabular}{|c|c|c|c|c|c|c|c|c|c|}
\hline Areia & Silte & Argila & $P$ & $\mathrm{~K}^{+}$ & $\mathrm{Ca}^{2+}$ & $\mathrm{Mg}^{2+}$ & $\mathrm{H}^{+}+\mathrm{Al}^{3+}$ & CTC & Saturação de bases \\
\hline--- & $(\%)$ & --- & $\left(\mu \mathrm{g} \mathrm{cm}^{-3}\right)$ & ---- & -----. & (meq 1 & $\left.\mathrm{~cm}^{-3}\right)--$ & ------ & $(\%)$ \\
\hline 68,3 & 5,1 & 26,6 & 1,5 & 0,02 & 0,50 & 0,78 & 2,77 & 1,30 & 3,2 \\
\hline
\end{tabular}

${ }^{1}$ Análise realizada antes da adubação, no Dep. de Solos, “Campus” Araras, UFSCar.

potencial hídrico e osmótico, conforme o método acima descrito.

\section{RESULTADOS E DISCUSSÃO}

Para normalizar a variância e avaliar corretamente as tendências de crescimento em cada tratamento, em algumas figuras, os dados foram expressos em forma de logaritmo natural.

Com relação à altura, observou-se que as plantas mais baixas foram as cultivadas em solo de cerrado sem fertilização. Entre 30 e 120 dias após a emergência (DAE), os maiores valores de altura foram encontrados em plantas cultivadas em solo com $1.500 \mathrm{~kg} \mathrm{ha}^{-1}$ de NPK, seguidas pelas crescidas em solo com $750 \mathrm{~kg} \mathrm{ha}^{-1}$ de NPK, e, finalmente, pelas que se desenvolveram em solo adubado com $3.000 \mathrm{~kg} \mathrm{ha}^{-1}$ de NPK. Após 120 DAE, a altura das plantas foi proporcional à concentração de adubo acrescentada, e as plantas crescidas em solo com $3.000 \mathrm{~kg} \mathrm{ha}^{-1}$ apresentaram o quádruplo da altura das cultivadas em solo sem adubo (Fig. 1).

A área foliar avaliada nas plantas cultivadas em solo de cerrado com diferentes teores de adubação está apresentada na Fig. 2. Esse parâmetro foi aumentando gradativamente até os 120 DAE, e após esse período os valores diminuíram, em decorrência dos processos de senescência e abscisão das folhas. Entre os diferentes tratamentos empregados, notou-se que a menor área foliar foi, geralmente, encontrada nas plantas crescidas em solo sem adubação, sendo observada clorose nas folhas a partir de 90 DAE. Com relação aos outros tratamentos, com 60 DAE, os maiores valores de área foliar foram encontrados em plantas cultivadas em solo com $1.500 \mathrm{~kg} \mathrm{ha}^{-1}$ de NPK. A partir de 90 DAE, os maiores valores de área foliar foram proporcionais à concentração de NPK adicionado ao solo, o que

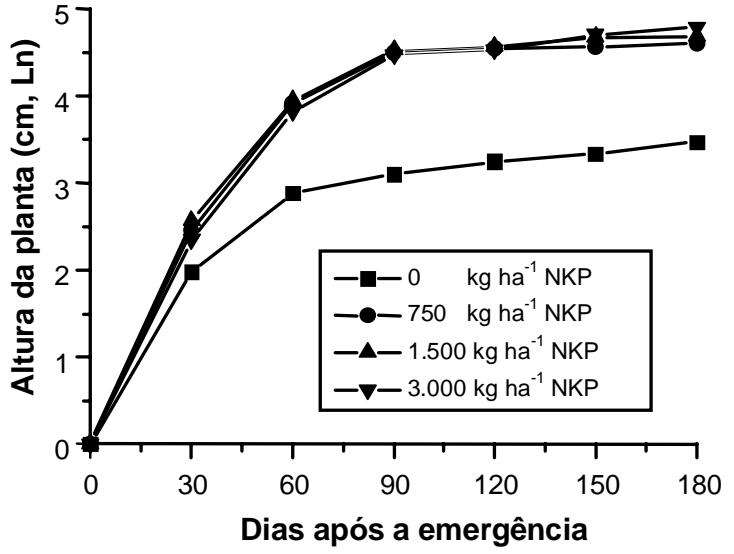

FIG. 1. Logaritmo dos valores médios da altura de leucenas cultivadas em solo de cerrado, com ou sem adição de NPK.

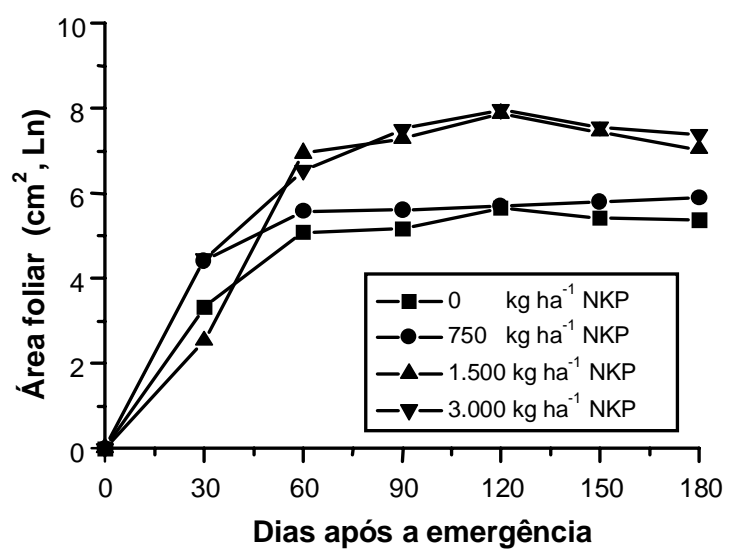

FIG. 2. Logaritmo dos valores médios da área foliar de leucenas cultivadas em solo de cerrado, com ou sem adição de NPK. 
confirma os estudos de Watson (1965), que ressalta a dependência da área foliar da nutrição mineral. Fanti (1996) observou que plantas de Adenanthera pavonina L. apresentaram valores de área foliar significativamente maior quando crescidas em solo fertilizado com NPK. No mesmo sentido, Scalon (1992) observou maiores valores de área foliar de Platycyamus regnelli quando foi utilizado solo fertilizado com NPK.

Sobre a produção de fitomassa (Fig. 3), maior acúmulo foi observado em vegetais crescidos em solos com maiores doses de adubo, a partir dos 90 DAE. A menor biomassa foi encontrada nas plantas cultivadas em solo de cerrado sem adubação. As diferenças na produção de matéria seca foram maiores do que as encontradas em altura, constatandose diferenças bastante nítidas entre os tratamentos com uma diferença percentual de $780 \%$ ao final do experimento.

Adenanthera pavonina (Fanti, 1996), Prosopis juliflora (Perez, 1995) e Adenanthera falcata (Perez, 1992) também apresentaram maior produção de fitomassa quando cultivadas em solo adubado.

A taxa de crescimento absoluto (Fig. 4) dá idéia da velocidade média do crescimento ao longo do período de observação. Os valores médios da velocidade de crescimento foram maiores em plantas cultivadas em solo adubado.

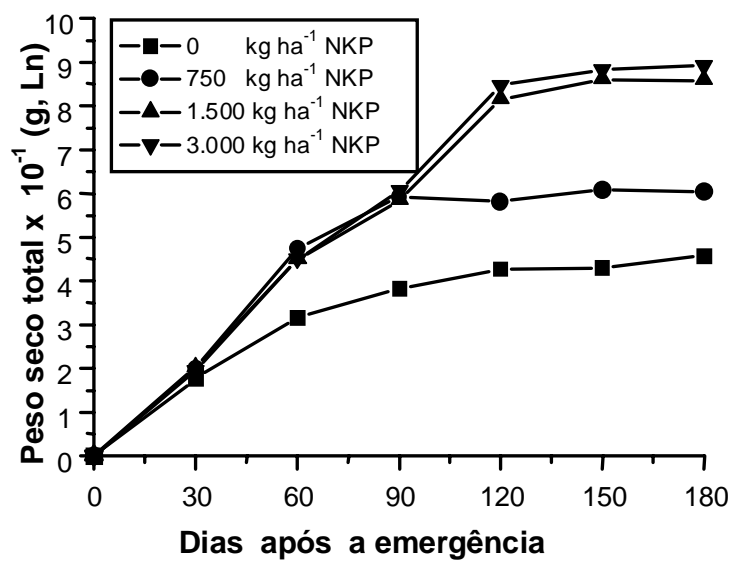

FIG. 3. Logaritmo dos valores médios do peso seco total de leucenas cultivadas em solo de cerrado, com ou sem adição de NPK.
Quanto à taxa de crescimento relativo (Fig. 5), verificou-se que entre 30 e $60 \mathrm{DAE}$ as plantas apresentaram maior impulso inicial de crescimento. Após 60 DAE, houve tendência ao decréscimo, ficando os maiores valores para as plantas cultivadas em solo com 1.500 e $3.000 \mathrm{~kg} \mathrm{ha}^{-1}$ de NPK. Tal decréscimo pode ter ocorrido pelo fato de a taxa ser dependente de dois outros parâmetros de crescimento: a razão de área foliar e taxa assimilatória líquida, que, por sua vez, dependem da área foliar.

A taxa assimilatória líquida (Fig. 6) foi superior, em média, em plantas crescidas em solo adubado com $750 \mathrm{~kg} \mathrm{ha}^{-1}$ de NPK. A taxa assimilatória líquida diminuiu com o tempo, devido ao processo de senescência e abscisão foliar; aos 180 dias havia pouca matéria fotossintetizante.

Com relação à taxa fotossintética (Fig. 7), podese dizer que os maiores valores foram observados em plantas adubadas com $750 \mathrm{~kg} \mathrm{ha}^{-1}$ de NPK até 120 DAE. Após esse período, as plantas que receberam maiores doses de adubo apresentaram maiores valores de taxa fotossintética.

A razão de área foliar (Fig. 8) não se manteve constante durante os experimentos, e diminuiu com a idade das plantas entre 30 e 90 DAE. No intervalo de 90 e 120 DAE houve um aumento desses valores, mas em seguida voltaram a diminuir, por causa de um decréscimo na área foliar em conseqüência

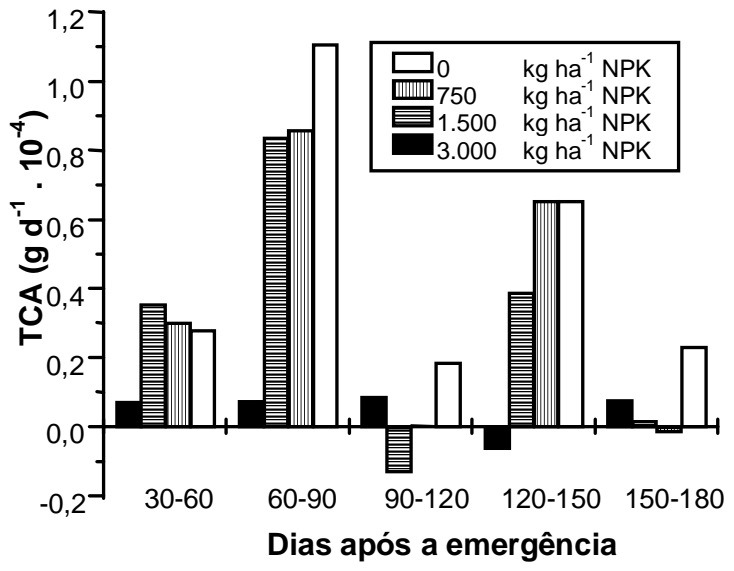

FIG. 4. Valores médios de taxa de crescimento absoluto (TCA) de leucenas cultivadas em solo de cerrado, com ou sem adição de NPK. 
do processo de senescência. A razão de área foliar pode ser encarada como a razão de matéria seca retida na folha e não exportada das folhas para o resto da planta. A maior ou menor exportação de material foliar é característica genética ou influenciada pelo ambiente.

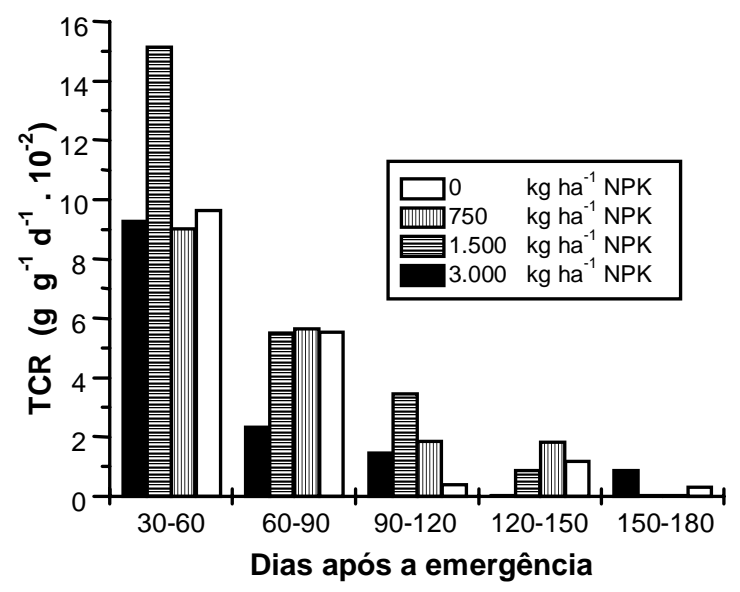

FIG. 5. Valores médios de taxa de crescimento relativo (TCR) de leucenas cultivadas em solo de cerrado, com ou sem adição de NPK.

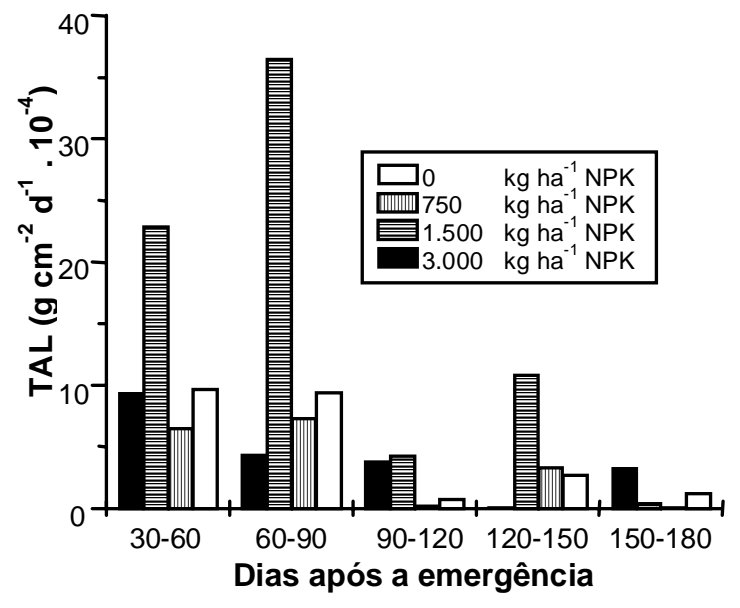

FIG. 6. Valores médios de taxa assimilatória líquida (TAL) de leucenas cultivadas em solo de cerrado, com ou sem adição de NPK.
No que se refere à razão de peso foliar, esse parâmetro apresentou diminuição gradativa, com o decorrer do tempo, em todos os tratamentos analisados (Fig. 9).

De acordo com Brandes et al. (1972), a razão de peso seco foliar representa a proporção de material

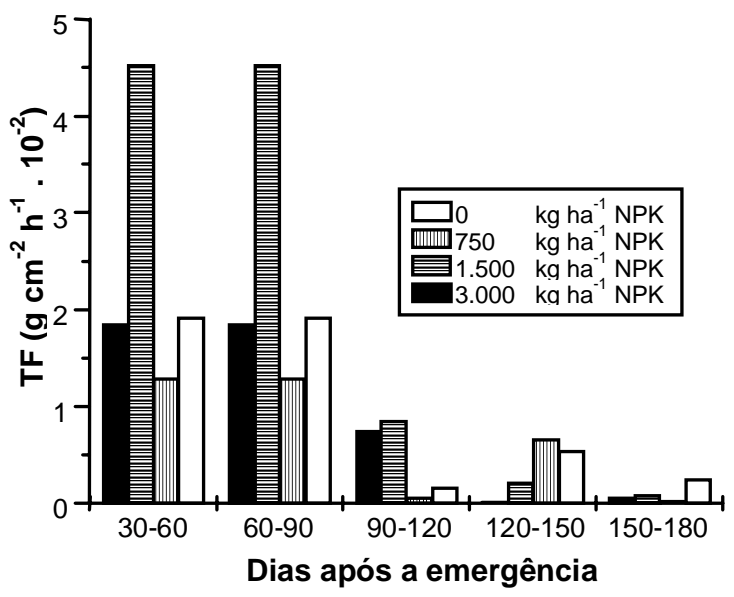

FIG. 7. Valores médios de taxa fotossintética (TF) de leucenas cultivadas em solo de cerrado, com ou sem adição de NPK.

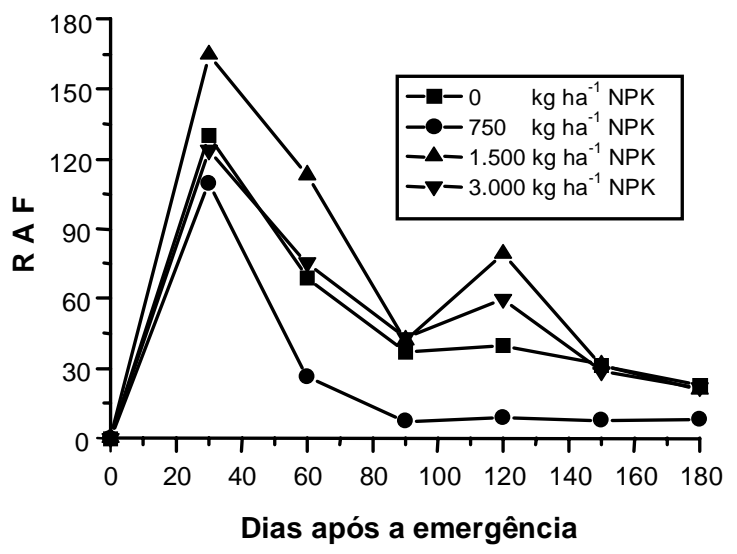

FIG. 8. Valores médios da razão de área foliar (RAF) de leucenas cultivadas em solo de cerrado, com ou sem adição de NPK. 
fotossintetizante em relação ao peso seco total das plantas, e apresenta tendência a um decréscimo contínuo com a idade, devido à biomassa não fotossintetizante, como flores e frutos e senescência dos folíolos.

A área foliar específica é um componente morfológico que oscilou bastante, com o decorrer dos experimentos, ficando os maiores valores com as plantas cultivadas em solos com $1.500 \mathrm{e}$ $3.000 \mathrm{~kg} \mathrm{ha}^{-1}$ de NPK (Fig. 10).

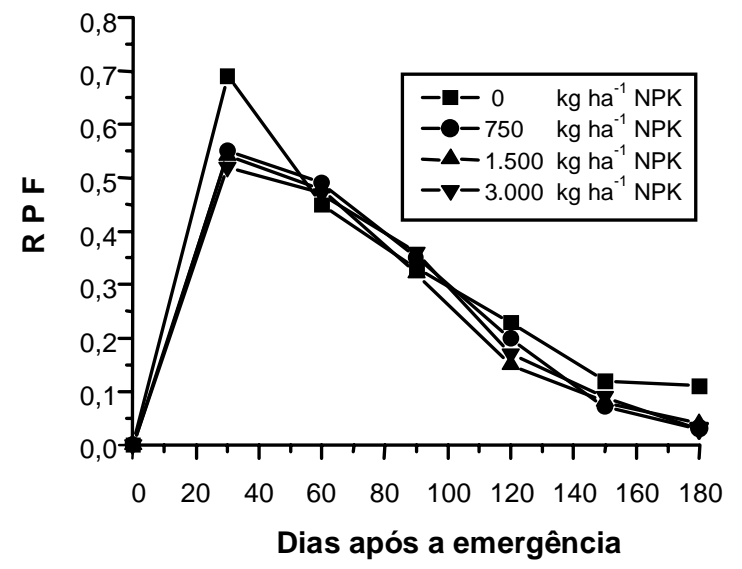

FIG. 9. Valores médios da razão de peso foliar (RPF) de leucenas cultivadas em solo de cerrado, com ou sem adição de NPK.

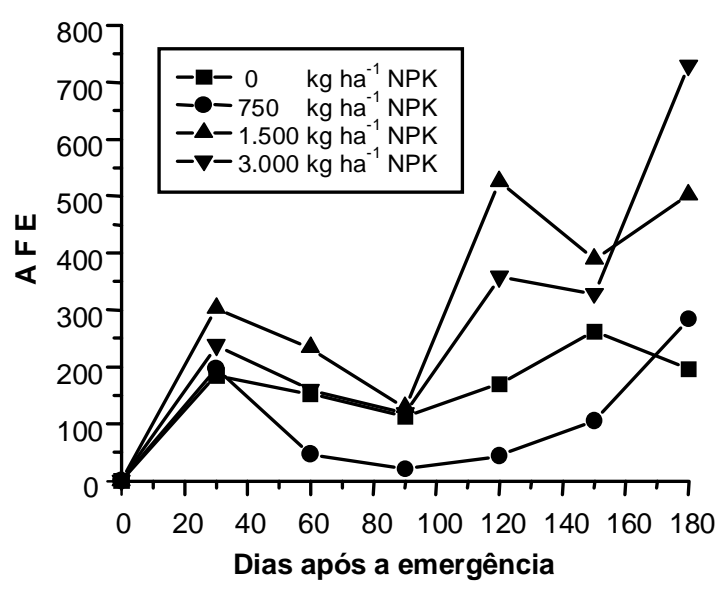

FIG. 10. Valores médios da área foliar específica (AFE) de leucenas cultivadas em solo de cerrado, com ou sem adição de NPK.
Quanto à distribuição de matéria orgânica entre os diferentes órgãos, verificou-se que as plantas cultivadas em solo fertilizado com NPK investiram maior quantidade de biomassa em caule (Fig. 11) do que em raízes (Fig. 12).

Com relação ao investimento em folhas, as plantas crescidas em solo adubado apresentaram maior proporção de matéria orgânica nesses órgãos até 90 DAE (Fig. 13).

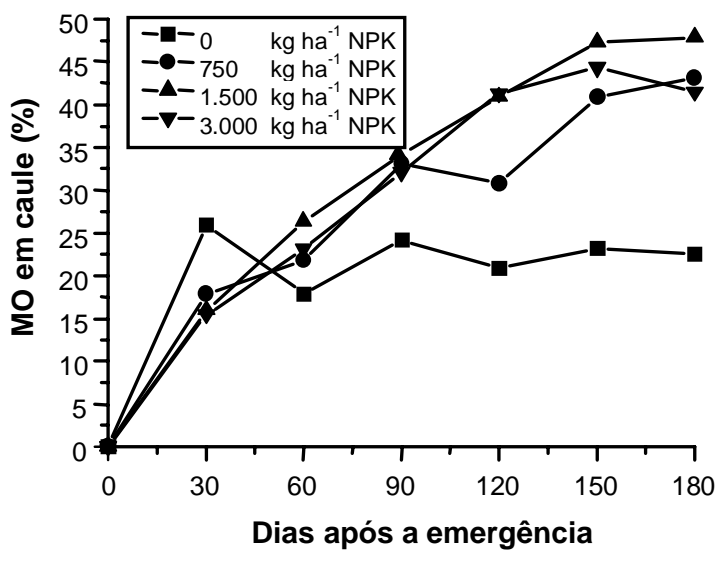

FIG. 11. Valores médios da porcentagem de matéria orgânica (MO) acumulada em caules de leucenas cultivadas em solo de cerrado, com ou sem adição de NPK.

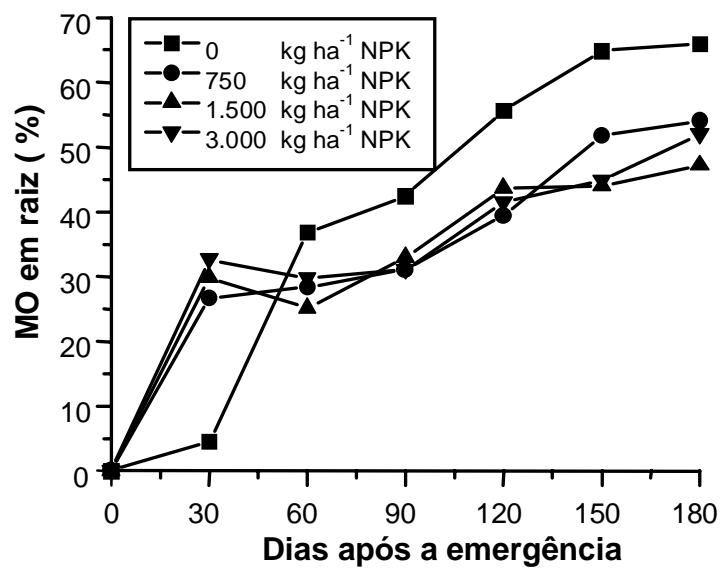

FIG. 12. Valores médios da porcentagem de matéria orgânica (MO) acumulada em raízes de leucenas cultivadas em solo de cerrado, com ou sem adição de NPK. 
A relação parte aérea/parte subterrânea foi diminuindo com a idade, e os menores valores foram obtidos em plantas cultivadas em solo sem fertilização, provavelmente devido a um maior investimento de matéria orgânica em raízes (Fig. 14).

Dessa forma, verifica-se que a nutrição mineral controla a proporção entre caules e raízes, e diferenças na proporção parte aérea e raízes ocorrem quando há diminuição de N e P (Ingestad \& Agren, 1992).

Com relação à fase reprodutiva, a presença de inflorescência só foi verificada em plantas cultivadas em solo fertilizado, a partir de 90 DAE. A presença de vagens ocorreu somente a partir de 150 DAE, em plantas crescidas em solo com 1.500 e $3.000 \mathrm{~kg} \mathrm{ha}^{-1}$ de NPK (Tabela 3).

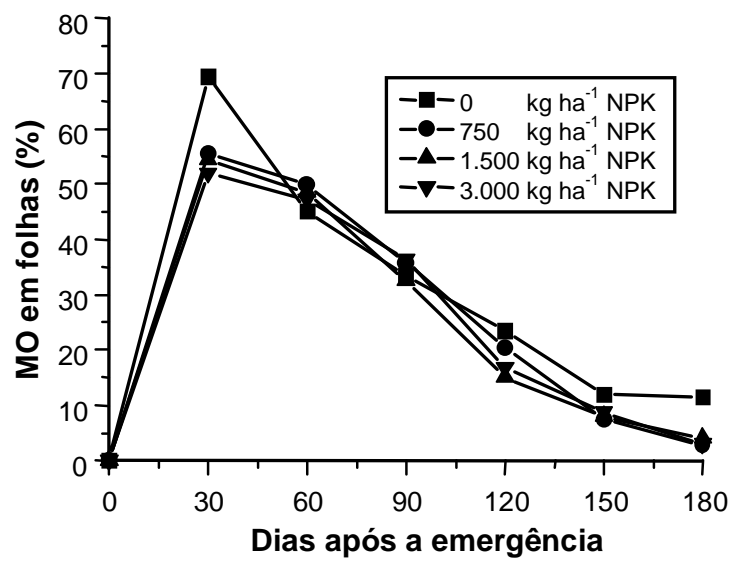

FIG. 13. Valores médios da porcentagem de matéria orgânica (MO) acumulada em folhas de leucenas cultivadas em solo de cerrado, com ou sem adição de NPK.
A avaliação de parâmetros biométricos e fisiológicos em seu conjunto revelou que Leucaena leucocephala respondeu à diferença nos níveis de adubação, crescendo mais em altura, área foliar e matéria seca. Tal crescimento resultou em antecipação do início da floração e frutificação nas plantas crescidas em solo adubado.

Skerman (1977) e Seiffert \& Thiago (1983) relataram também que em solos ácidos e pobres, plantas de leucena apresentaram baixa taxa de crescimento, permanecendo na forma de arbustos.

Visando à produção de mudas para múltiplos usos, tem sido analisado o efeito de diferentes tipos de solo no crescimento de espécies arbóreas. O melhor desenvolvimento de Kielmeyera coriacea ocorreu em solo de mata, e não em solo de cerrado

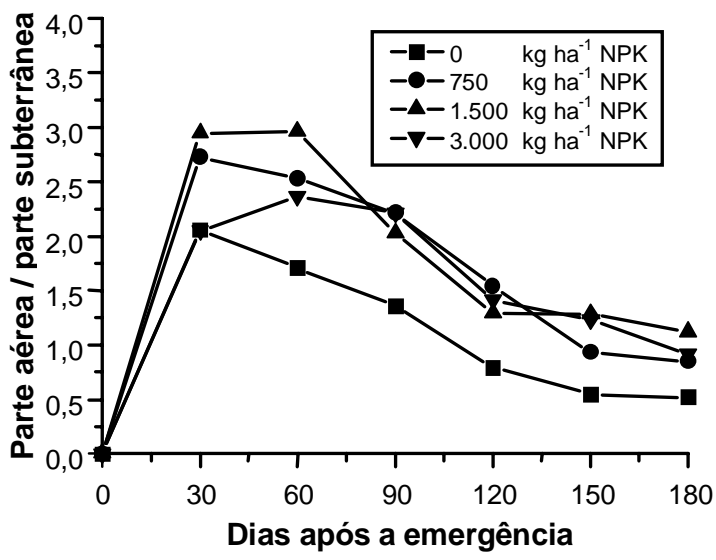

FIG. 14. Valores médios da proporção parte aérea/parte subterrânea de leucenas cultivadas em solo de cerrado, com ou sem adição de NPK.

TABELA 3. Valores médios da porcentagem de matéria orgânica investida em flores e em frutos de leucenas cultivadas em casa de vegetação, em solo de cerrado com $750,1.500$ e $3.000 \mathrm{~kg} \mathrm{ha}^{-1}$ de NPK (4-14-8).

\begin{tabular}{lccccccc}
\hline \multirow{2}{*}{$\begin{array}{c}\text { Dias após } \\
\text { a emergência }\end{array}$} & \multicolumn{2}{c}{ Matéria orgânica investida em flores $(\%)$} & & \multicolumn{3}{c}{ Matéria orgânica investida em vagens (\%) } \\
\cline { 2 - 3 } \cline { 6 - 8 }$n$ & 750 & 1.500 & 3.000 & & 750 & 1.500 & 3.000 \\
\hline 90 & 0,00 & 0,31 & 0,57 & & 0,00 & 0,00 & 0,00 \\
120 & 0,15 & 0,35 & 0,55 & & 0,00 & 0,00 & 0,00 \\
150 & 0,02 & 0,49 & 0,41 & & 0,00 & 0,33 & 1,85 \\
180 & - & - & - & & 0,00 & 0,77 & 3,55 \\
\hline
\end{tabular}


(Dionello, 1978). Astroneum urundeuva cresceu em solo de cerrado, mas o melhor desenvolvimento foi verificado quando se adicionaram fertilizantes químicos no solo (Melo et al., 1981). Vochisia tucanorum (Machado, 1985) cresceu em solo de cerrado e mata galeria, porém Dimorphandra mollis se desenvolveu melhor em solo de floresta (Mendes, 1991). Fanti (1996) encontrou melhores condições para produção de mudas de Adenanthera pavonina quando utilizou solo de cerrado fertilizado com NPK.

Nas Figs. 15 e 16 estão os valores de potencial hídrico foliar de plantas cultivadas em casa de vegetação desde a suspensão da rega até a reirrigação. As plantas cultivadas em solo sem fertilização murcharam e perderam todas as folhas, impedindo assim as determinações de potencial hídrico e osmótico. Leucenas com 90 DAE resistiram sem rega por mais tempo (30 dias) com potencial hídrico mais negativo (em torno de $-2,0 \mathrm{MPa}$ ), sem murchar, do que as com 30 DAE (20 dias) (potencial hídrico em torno de -1,6 MPa).

Os valores de porcentagem de água no solo após o estresse em plantas adubadas com 0, 750, 1.500 e $3.000 \mathrm{~kg} \mathrm{ha}^{-1}$ de NPK foram, respectivamente, $8,75 \%, 10,0 \%, 9,85 \%$ e $10,25 \%$, em plantas com
30 DAE, e $8,48 \%, 8,22 \%, 8,92 \%$ e $8,50 \%$, em plantas com 90 DAE.

Plantas com 30 DAE adubadas com 1.500 e $3.000 \mathrm{~kg} \mathrm{ha}^{-1}$ de NPK mantiveram maior teor de água nos tecidos (potencial hídrico $=-1,60 \mathrm{MPa}$ ) do que as dos solos sem fertilização e com $750 \mathrm{~kg} \mathrm{ha}^{-1}$ de NPK (-1,80 MPa) (Fig. 15). Com relação às plantas com 90 DAE (Fig. 16), foi observado um decréscimo mais acentuado nos valores de potencial hídrico, em indivíduos crescidos em solo sem fertilização.

A Tabela 4 contém os valores de potencial osmótico obtidos antes e depois da aplicação do estresse hídrico simulado em plantas com 30 e 90 DAE, cultivadas em solo com ou sem adição de NPK. Os vegetais crescidos em solo sem fertilização com 30 e 90 DAE e em solo com $750 \mathrm{~kg} \mathrm{ha}^{-1}$ de NPK com 30 DAE perderam as folhas após 20 dias sem rega, e não puderam ser obtidos os valores de potencial osmótico após o estresse. Aos 30 DAE, observou-se redução dos valores de potencial osmótico após aplicação do estresse hídrico em plantas crescidas em solo com $1.500 \mathrm{~kg} \mathrm{ha}^{-1} \mathrm{e}$ $3.000 \mathrm{~kg} \mathrm{ha}^{-1}$ de NPK, respectivamente. Quanto às plantas com 90 DAE, o percentual médio de decréscimo de potencial osmótico após o estresse hídrico foi em torno de $10,5 \%$ em plantas crescidas em so-

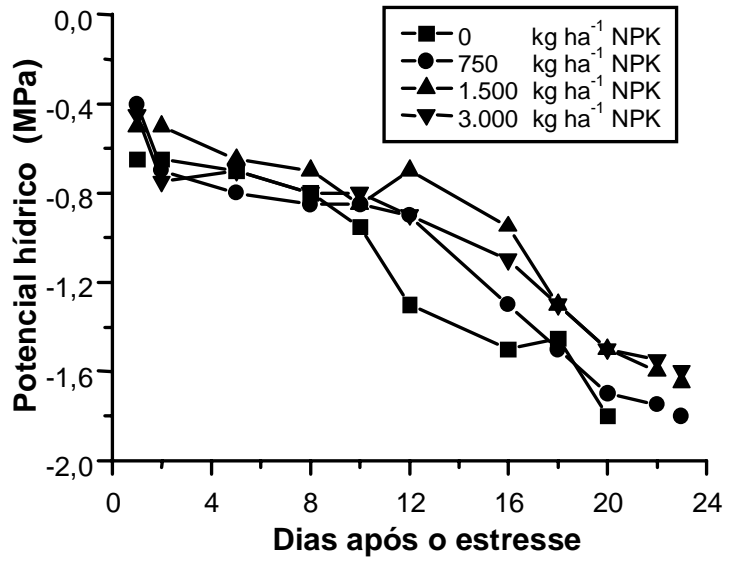

FIG. 15. Valores médios do potencial hídrico foliar durante estresse hídrico simulado em leucenas com 30 DAE cultivadas em solo de cerrado, com ou sem adição de NPK.

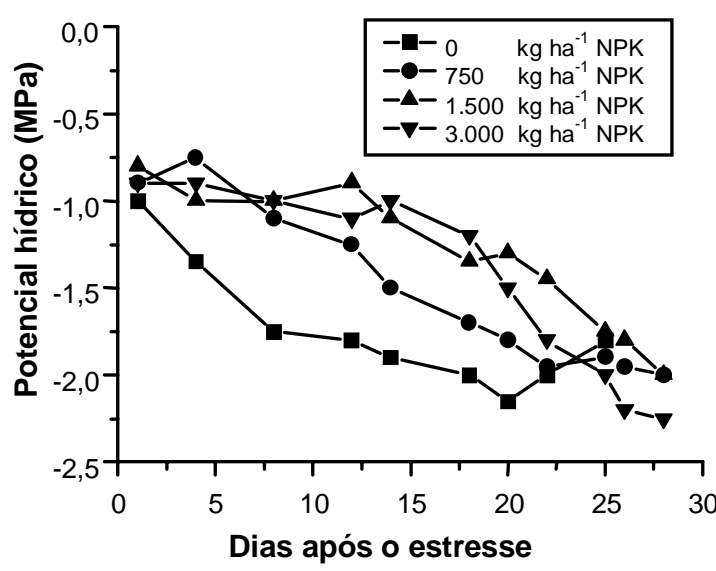

FIG. 16. Valores médios do potencial hídrico foliar durante estresse hídrico simulado em leucenas com 90 DAE cultivadas em solo de cerrado com ou sem adição de NPK.

Pesq. agropec. bras., Brasília, v.34, n.6, p.933-944, jun. 1999 
TABELA 4. Valores médios do potencial osmótico $(\pi)$ (MPa) de leucenas cultivadas em casa de vegetação antes e após a aplicação do estresse hídrico simulado pela suspensão da rega ${ }^{1}$.

\begin{tabular}{|c|c|c|c|c|c|}
\hline \multirow[t]{2}{*}{ Solo de cerrado } & \multicolumn{2}{|c|}{ Antes do estresse } & \multicolumn{2}{|c|}{ Após o estresse } & \multirow{2}{*}{$\begin{array}{c}\text { Decréscimo } \\
(\%)\end{array}$} \\
\hline & $\psi \pi_{0}$ & $\psi \pi_{100}$ & $\psi \pi_{0}$ & $\psi \pi_{100}$ & \\
\hline & \multicolumn{5}{|c|}{30 dias após a emergência } \\
\hline Sem NPK & $-2,00$ & $-1,96$ & $-2,00$ & $-1,96$ & 0,0 \\
\hline $750 \mathrm{~kg} \mathrm{ha}^{-1} \mathrm{NPK}$ & -1 & - & - & - & - \\
\hline $1.500 \mathrm{~kg} \mathrm{ha}^{-1} \mathrm{NPK}$ & $-1,66$ & $-1,47$ & $-1,90$ & $-1,60$ & 11,29 \\
\hline \multirow[t]{2}{*}{$3.000 \mathrm{~kg} \mathrm{ha}^{-1} \mathrm{NPK}$} & $-1,47$ & $-1,10$ & $-1,70$ & $-1,38$ & 12,54 \\
\hline & \multicolumn{5}{|c|}{90 dias após a emergência } \\
\hline Sem NPK & $-1,80$ & $-1,69$ & - & - & - \\
\hline $750 \mathrm{~kg} \mathrm{ha}^{-1} \mathrm{NPK}$ & $-1,68$ & $-1,53$ & $-1,92$ & $-1,66$ & 10,84 \\
\hline $1.500 \mathrm{~kg} \mathrm{ha}^{-1} \mathrm{NPK}$ & $-1,84$ & $-1,66$ & $-1,96$ & $-1,74$ & 10,50 \\
\hline $3.000 \mathrm{~kg} \mathrm{ha}^{-1} \mathrm{NPK}$ & $-2,08$ & $-1,93$ & $-2,17$ & $-2,04$ & 10,56 \\
\hline
\end{tabular}

${ }^{1}$ As plantas perderam as folhas.

los fertilizados com NPK. Uma das estratégias utilizadas pelas plantas para tolerarem a seca é o ajuste osmótico, que permite ao vegetal manter a turgescência mesmo sob baixos valores de potencial hídrico. Comparando-se os valores dos potenciais osmóticos antes e depois do estresse hídrico, em termos percentuais, verificou-se a ocorrência de um decréscimo superior a 10\%. Esses decréscimos no potencial osmótico confirmam o valor estipulado $(10 \%)$ em outros estudos com referência a plantas pré-condicionadas (Steponkus et al., 1980), o que indica a existência de um ajuste osmótico, já sugerido em relação a outras espécies lenhosas cultivadas em casa de vegetação (Prado, 1991; Rocha, 1994; Perez, 1995).

O último aspecto abordado neste estudo foi a resposta de recuperação ao estresse hídrico, a qual ocorreu mais rapidamente nas plantas de solos fertilizados tanto aos 30 DAE quanto aos 90 DAE, dada a perda das folhas. As leucenas crescidas em solo adubado recuperaram-se em 48 horas (valores de potencial hídrico $=-0,5 \mathrm{MPa}$ ). Prado (1991) também observou recuperação do estresse hídrico induzido em Copaifera langsdorfii em um período de 48 horas.

Perez (1992, 1995) avaliando a resistência à seca em Prosopis juliflora e Anadenanthera falcata, ve- rificou maior tolerância à dessecação em plantas mais velhas, cultivadas em solo de cerrado com fertilização e uma resposta de recuperação ao estresse hídrico em menos de 24 horas.

\section{CONCLUSÕES}

1. As plantas de Leucaena leucocephala tipo Peru, cultivar Cunninghan, respondem à aplicação de fertilizante químico, crescendo mais em altura, área foliar e matéria seca, e antecipando a floração.

2. As plantas crescidas em solo adubado resistem mais à seca do que as crescidas em solo sem adubo.

3. Um ajuste osmótico auxilia as plantas a sobreviverem ao estresse hídrico.

\section{REFERÊNCIAS}

BENINCASA, M.M.P. Análise de crescimento de plantas: noções básicas. Jaboticabal: Funesp, 1988. 42p.

BLOM, P.S. Leucaena, a promising versatile leguminous tree for the tropics. Abstracts on Tropical Agricultura, v.6, n.3, p.9-17, 1980.

BRANDES, D.; VIEIRA, C.; MAESTRI, M.; GOMES, F.R. Efeitos da população de plantas e da época de plantio no crescimento do feijoeiro (Phaseolus 
vulgaris L.). I - Mudanças morfológicas e produção de matéria seca. Experientia, v.14, p.1-49, 1972.

BREWBAKER, J.L. Leucaenas for the highland tropics. Leucaena Research Reports, Tailândia: Taipei, v.7, p.14-16, 1987.

CAMARGO, A.P.; PINTO, H.S.; BRUMINI, O.B.; PEDRO, M.S.J.; ORTOLONI, A.A.; ALFONSI, R.R. Zoneamento agrícola do Estado de São Paulo: clima do Estado de São Paulo. São Paulo: Secretaria da Agricultura do Estado de São Paulo, 1974. v. $1,78 p$

DIONELLO, S.P. Germinação de sementes e desenvolvimento de plântulas de Kielmeyera coriaceae Mart. São Paulo: Instituto de Biociências, 1978. 123p. Dissertação de Mestrado.

FANTI, S.C. Comportamento germinativo sob condições de estresse e influência do sombreamento artificial e adubação química na produção de mudas de Adenanthera pavonina L. São Carlos: UFSCar, 1996. 153p. Dissertação de Mestrado.

FREITAS, A.R.D.; OLIVEIRA, A.L.P.C.D.; SILVA, B.A. da; DECICO, M.J.U. Leucaena leucocephala Lam. (de Witt): cultura e melhoramento. São Carlos: Embrapa-UEPAE/São Carlos, 1991. 93p. (Documento 12).

GUPTA, A.S.; BERKOWITZ, G. A. Osmotic adjustment, symplast volume, and nonstomatally mediated water stress inhibition on photosynthesis in wheat. Plant Physiology, v.85, n.4, p.1040-1047, 1987.

INGESTAD, T.; AGREN, G.I. Theories and methods on plant nutrition and growth. Physiologia Plantarum, v.84, p.177-184, 1992.

LIMA, P.C.F. Comportamento de leucena comparado com algaroba e Eucalyptus em Petrolina (PE): região semi-árida do Brasil. Curitiba: Universidade Federal de Curitiba, 1982. 92p. Dissertação de Mestrado.

LIMA FILHO, J.M.P.; DRUMOND, M.A.; MACENO, D. da S. Comportamento fisiológico de Leucena e Albizia sob condições semi-áridas. Pesquisa Agropecuária Brasileira, Brasília, v.27, n.4, p.537542, abr. 1992.

MACHADO, J.W.B. Acúmulo de alumínio em Vochisia thripoidea. Brasília: Universidade de Brasília, 1985. 104p. Dissertação de Mestrado.
MELKONIAN, J.J.; WOLFE, J.; STEPONKUS, P.L. Determination of the volumetric modulus of elasticity of wheat leaves by pressure/volume relations and the effect of drought conditions. Crop Science, v.22, p.116-123, 1982.

MELO, J.T. de; LIMA, V.L.G. de F.; RIBEIRO, J.S. Desenvolvimento inicial de Astroneum urundeuva (Fr. All.) Engl. (Aroeira) em diferentes tipos de solo da região dos cerrados. In: CONGRESSO NACIONAL DE BOTÂNICA, 1981, Teresina. Anais... Teresina: FUFPI, 1981. p.283-298.

MENDES, J.A. Estudo do crescimento, composição mineral e conteúdo de clorofila de plantas jovens de Dimorphandra mollis Benth. Rio Claro: UNESP, 1991. 141p. Dissertação de Mestrado.

MITIDIERI, J. Manual de gramíneas e leguminosas para pastos tropicais. São Paulo: Nobel/EDUSP, 1983. $198 \mathrm{p}$.

MIYASAKA, S.; CAMARGO, O.A. de; CAVALIERI, P.A. Adubação orgânica, adubação verde e rotação de culturas nos estado de São Paulo. Campinas: Fundação Cargill, 1983. 138p.

NATIONAL ACADEMY OF SCIENCE. Leucaena, promising forage and tree crop for the tropics. Washington: National Research Council, 1977. $115 \mathrm{p}$.

NOGUEIRA, F.D.; PAULA, M.B. de; GUIMARÃES, P.T.G.; TANAKA, T. Adubação verde, fosfato natural e gesso para a cultura de mandioca em latossolo roxo textura argilosa. Pesquisa Agropecuária Brasileira, Brasília, v.27, n.3, p.357-372, mar. 1992.

PAULILO, M.T.S.; FELIPPE, G.M.; DALE, J.E. Crescimento inicial de Qualea grandiflora. Revista Brasileira de Botânica, v.16, n.1, p.37-46, 1993.

PEREZ, S.C.J.G. de A. Análise de crescimento e comportamento da planta jovem de Adenanthera falcata (Benth) Speg sob estresse hídrico. Vegetalia, v.28, p.1-29, 1992.

PEREZ, S.C.J.G. de A. Crescimento e resistência à seca de algarobeira (Prosopis juliflora, Sw D.C.) cultivadas em solo de cerrado com ou sem adubo orgânico. Pesquisa Agropecuária Brasileira, Brasília, v.30, n.5, p.595-604, maio 1995.

PRADO, C.H.B. de A. Trocas gasosas em planta jovem de Copaifera langsdorffii, Desf., durante estresse hídrico induzido artificialmente por ausência de

Pesq. agropec. bras., Brasília, v.34, n.6, p.933-944, jun. 1999 
rega. São Carlos: UFSCar, 1991. 94p. Dissertação de Mestrado.

ROCHA, A.M. dos S. Estresse hídrico e trocas do CO gasoso e vapor d'água em plantas jovens envasadas de Stryphnodendron adstringens (Mart.) Coville. São Carlos: UFSCar, 1994. 123p. Dissertação de Mestrado.

SALERNO, A.R.; SEIFFERT, N.F. Leucena - características agronômicas e recomendação de manejo. Florianópolis: EMPASC, 1986. 10p. (EMPASC. Boletim técnico, 105).

SALERNO, A.R.; TCACENCO, F.A. Leguminosas forrageiras para o Baixo Vale do Itajaí. Florianópolis: EMPASC, 1983. 4p.

SALERNO, A.R.; VETTERLE, C.P. Leguminosas perenes de estação quente para o Baixo do Itajaí. Florianópolis: EMPASC, 1983. 4p. (EMPASC. Boletim técnico, 30).

SCALON, S.P.Q. Estudo da germinação de sementes e produção de mudas de pau-pereira (Platycyammus regnelli Benth). Lavras: ESAL, 1992. 63p. Dissertação de Mestrado.
SCHOLANDER, P.F.; HAMMEL, H.T.; HAMMINGSEN, E.A.; BRADSTREET, E.D. Hidrostatic pressure and osmotic potential of mangane and some other plants. Proceedings of the National Academy of Science, v.52, p.112-119, 1964.

SCHOLANDER, P.F.; HAMMEL, H.T.; HAMMINGSEN, E.A.; BRADSTREET, E.D. Sap pressure in vascular plants. Science, v.148, p.339$346,1965$.

SEIFFERT, N.F.; THIAGO, L.R.L. de. Legumineira cultura forrageira para produção de proteína. Campo Grande: Embrapa-CNPGC, 1983. 52p. (Embrapa-CNPGC. Circular técnica, 13).

SKERMAN, P.J. Tropical forage legumes. Roma: FAO, 1977. 609p.

STEPONKUS, P.L.; SHANAN, K.N.; CUTLER, J.M. Osmotic adjustment in rice. Los Banos: International Rice Research Institute, 1980. p.181-194.

WATSON, D.S. The physiological basis of variation in yield. Advances in Agronomy, v.4, p.101-145, 1965. 